\title{
AndroiDuino-Fan: A Speech Recognition Fan-Speed Control System utilizing Filipino Voice Commands
}

\author{
Jesusimo L. Dioses, Jr. \\ Isabela State University, Echague, Isabela, Philippines,jdiosesjr@ gmail.com
}

\begin{abstract}
In today's modern world, smart homes are now in demand. The times have now become the thing of the past since, over the last few decades, home automation has gained several milestones and acclaim, mainly limited to sci-fi videos. Compared with days gone by, home automation has brought a whole new definition to life. A controller controlled the devices which can be located at home, such as television, air conditioning, lighting, electric fans, etc. These devices can also be controlled by only one remote control instead of one remote control per system. The problems with this paper solve the problem. Only use an existing Bluetooth transmission with an Arduino and smartphone. The voice recognition using Filipino language was used for automatically controlled the electric fan speed from speed no.1 to speed no. 4. The user makes use of voice commands to perform certain actions. In the testing conducted, the fan speed 1 and 2 obtained 50\% accuracy and for speed no. 3 and 4 both obtained $100 \%$ accuracy. The testing shows a promising result. When it comes to functional testing of the system, the system will function effectively.
\end{abstract}

Key words: Android, Arduino Microcontroller, Bluetooth, Filipino Language Voice Commands, Smart Home, Voice Controlled.

\section{INTRODUCTION}

Electronic devices are used in each individual's daily activities [1]. The handling of these devices in the current period involves the use of a remote controller. The functionalities and operations vary from device to device [2]. Mobile apps and remote controls are the brain-numbing task for the elderly and the disabled [3]. Particularly for visually impaired people, the remote controls that belong to specific home appliances are hard to recognize [4]. It can be done with a significantly more expensive home appliance automation device, which is not affordable by ordinary citizens [5]. The real innovation is effectively done because it is made accessible and inexpensive for any economic community. The objective of this paper for those older and disabled persons. For them to control devices like light, fan, heater, TV, etc. at home, by giving the command through the voice [6]. This study aims to develop a system that is relatively affordable, simple to implement, or configure and users friendly.
There are various commercial and research projects available in the market on a voice recognition system [7]. There are lots of possible solutions to this issue. But those kinds of automation are still not very popular due to the expensive price in the market. The usage of current products will render things much better, instead of producing a new one. Mobile phones today are the growing devices that any single man uses. This method is a good one because it has a microphone and smartness in various applications [8].

There is research that focuses on a smart home application that uses the IoT or Internet of Things [9]. The network exists for the home, where any computer attached to the network can use other equipment or home appliances. [10]. The main aspect of the study is the use of movements based on speed and temperature for certain systems for ceiling fans, and the light can even be switched on or off automatically by using the light sensor inputs [11]. This is a secure program since, without user verification, nobody can access the web program.

Nowadays many companies in the Philippines use various engine speed control technology [12]. Fan speech recognition control and command device increases its efficiency to allow the user to use the equipment with ease [13]. Voice recognition of fan speed control is a project in which users need voice commands to power the AC motor [14]. This design implementation includes the wireless automation of electric fan loads by providing voice commands for remote communication with the appliance control module using smartphones and the Bluetooth Module.

This research is to operate a voice-commanded electric fan. The fan will understand spoken commands to travel and react correctly in terms of pace. The voice command is first transferred to one's mobile phone to give the electric fan a direction. It recognizes the voice recognition command, and then turns the voice command into a pre-defined direction command and is easily recognizable by the programmed keywords. If the electric fan is controlled, it moves as per the spoken command. 


\section{METHODOLOGY}

\subsection{Proposed Design}

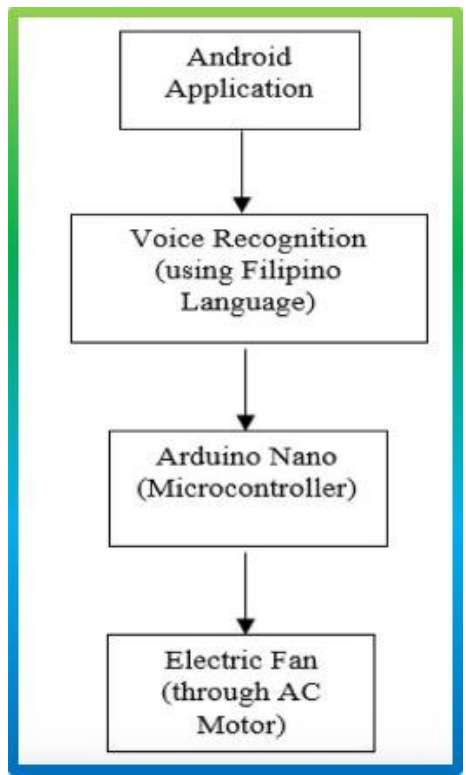

Figure 1: The Block Diagram of the System

Figure 1 shows the system's block diagram consisting of different modules such as an android program, voice recognition using Filipino language, Arduino Nano, electric fan using AC motor. A voice input that transforms the voice order into an electric signal is specifically provided to the Microphone. For speech recognition, the mic signal is fed into the processor. The first phase in speech recognition is to say a single word or phrase via a microphone.As the voice within each person is different, the voice of a new user must first be trained as an input in the program, before the system can recognize the voice of that person. The qualified tone is used to evaluate a statistical average of different samples of the same term, storing the average sample in a data structure of the system as a prototype. When the average sample matches an already stored sample then the receiver takes the corresponding signal. To control the devices the device control program is stored in the memory. The required signal is transmitted from the controller over Bluetooth.

\subsection{Filipino language Voice Recognition}

Voice recognition is a device that converts sounds and spoken words into electrical signals and translates these signals into encoder models of language. This concept could more often be called a sound recognition or recognition of speech [15].

The human voice is based here primarily, as we use voices more instinctively and frequently to express our thoughts to others in immediate environments [16]. For speech recognition, the first item is the compilation of speaker details. Voiced language collection is created from multiple speaking samples such that all samples with the necessary speech data are collected and processed [17].The signal analyzer transmits the sample data to the acoustic model [18]. Language models are provided samples of potential speech data. Such alternatives are related to previously qualified model results. The most likely speaker data is chosen as the correct data and given as output.

\subsection{Hardware Design}

The following hardware components were Arduino Nano, Bluetooth Module (HC-05), Android-based smartphones, connecting wires, and electric fan used in this study.

\subsubsection{Arduino Nano}

Arduino Nano is a thin, ATMega328 compatible breadboard device. It has comparable functionality to the Arduino Uno but operates with a Mini-B USB link in the case of a DIP-module. Arduino has a lot of application such as in wireless electric fan control using gestures [19], rice straw decomposition system [20], smart knock security drawer [21], soil moisture control [22], automatic humidifier [23], and even in detecting the drowsiness [24], tracking [25].

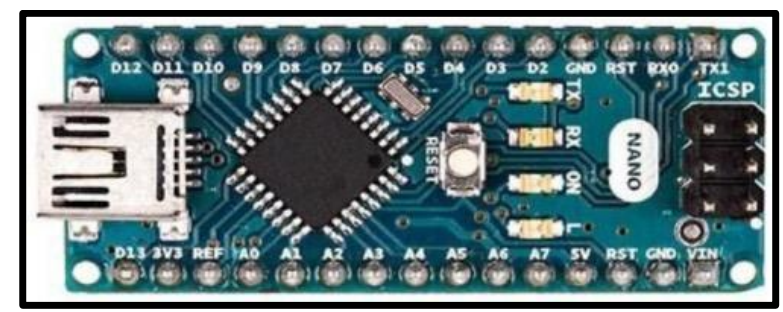

Figure 2: Arduino Nano

The detailed specification of the Arduino Nanoboard are as follows:

1) Microcontroller ATmega 328

2) Operating Voltage (logic level): $5 \mathrm{~V}$

3) Input Voltage (Recommended): 7-12 V

4) Input Voltage (limits): 6-20 V

5) Digital I/O Pins: 14 (of which 6 provide PWM

6) Output)

7) Analog Input Pins: 8

8) DC Current per I/O Pin: $40 \mathrm{~mA}$

9) Flash Memory $32 \mathrm{~KB}$ (ATmega328) of which 2

10) KB used by a boot loader

11) SRAM: 2 KB (ATmega328)

12) EEPROM: $1 \mathrm{~KB}$ (ATmega328)

13) Clock Speed: $16 \mathrm{MHz}$

14) Measurements: 0.73" x 1.70"

\subsubsection{Bluetooth Module}

For Bluetooth connectivity, the HC-05 module is used in this work. It is needed for wireless, transparent communication setup, Master/Slave configuration of the module can be used as a better solution for wireless communication. The module is a Bluetooth V2.0 with EDR. Moreover, it has a $2.4 \mathrm{GHz}$ transceiver and baseband. 


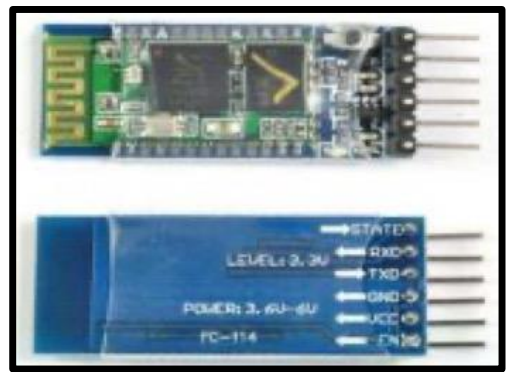

Figure 3: Bluetooth Module HC-05

The specification of Bluetooth Module (figure 3) is the following:

1) Bluetooth Version: V2.0 EDR

2) Frequency: $2.4 \mathrm{GHz}$

3) Dissipated power: $\leq 4 \mathrm{dBm}$

4) Sensitivity: $\leq-84 \mathrm{dBm}$

5) 5.Speed: Asynchronous: 2.1Mbps (max) / $160 \mathrm{kbps}$

6) 6.Synchronous: Encryption and Authentication

7) 7. Input Voltage and Current: 3.3VDC, $50 \mathrm{~mA}$

8) 8.Working Temperature: $-15-75$ Centigrade

9) 9. Dimension: $27 \mathrm{~mm} \times 13 \mathrm{~mm} \times 2 \mathrm{~mm}$

a. Hardware Features

- Sensitivity: $-80 \mathrm{dBm}$

- RF transmits power up to $+4 \mathrm{dBm}$

- Input/output can be controlled by programming them. It is the programming environment used for the implementation of this project.

b. Software Features

- Default Baud rate: 9600, Data bits: 8, Stop bit:1, No parity

- Auto-connect to the last device on power as default

- Permit pairing devices to connect as default

- Default auto-pairing PINCODE:"1234"

\subsubsection{AC Motor}

$\mathrm{AC}$ Motor is a motor powered by alternating current. In electrical energy conversion into mechanical energy, the AC Motor is used. This mechanical energy consists of the use of force through rotating magnetic fields produced by the alternating current which runs through its coils. The AC motor contains two main components: the stationary outside stator which is equipped with $\mathrm{AC}$ control coils and the inner rotor which is mounted on the output shaft.

AC Motor(figure 4) depends on the laws of magnetism for its basic purpose. The AC Motor comprises a wire coil and two magnets along a tube. As a voltage is added to the wire loop, the electromagnetic charging is a magnetic field. The spring and the spiral of the wires continue to spin, driving the motor, already mentioned, when the magnets connect.

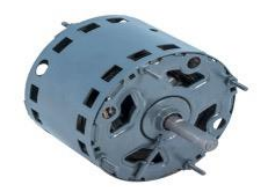

Figure 4: AC Motor

\subsection{Software Design}

A text editor for write code, a message area, a text console, a toolbar with common function buttons and several meals are available in the Arduino Integrated Development Environment or Arduino Software ( IDE) -.It links to the computers Arduino and Genuino to access and interact with programs. It is the programming framework used for this project.

\section{TESTING AND RESULTS}

As Figure 5 below shows, the proponents of this project integrated the use of Bluetooth-based voiced control system into a commercial electric fan to implement a smartphone-controlled Internet-of-Things-type electric fan. The user can connect to the android application to control the AC Motor as seen in Figure 6 and 7 Through the AC motor of the fan, the speed can now be controlled based on the desire of the user. Moreover, the speech implemented in the project is the Filipino language for the fan speed and off command "isa" (one), "ikalawa" (second), "ikatlo" (third), and "patayin" (OFF).

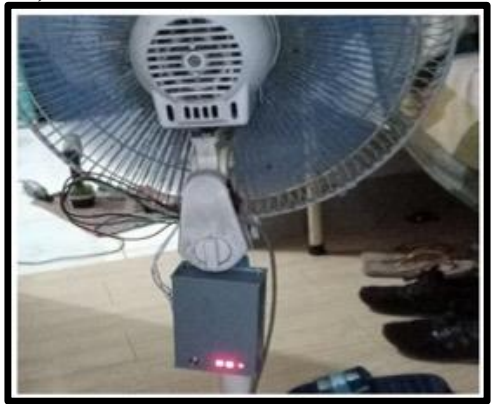

Figure 5: Voice- Controlled Fan.

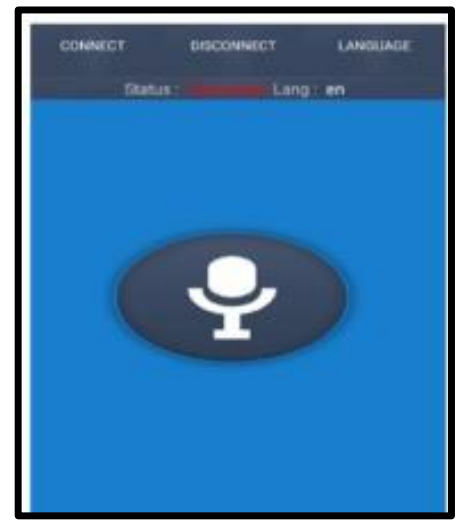

Figure 6: Voice Control Application

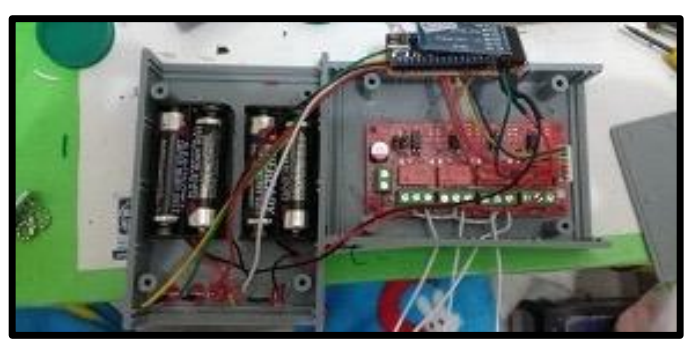

Figure 7: Prototype assembly 
Table 1: Fan Speed No.1 Testing Results

\begin{tabular}{rrrr}
\hline \hline \multicolumn{1}{c}{ Voice Input } & \multicolumn{1}{c}{ Expected Output } & \multicolumn{1}{c}{ Actual Output } & \multicolumn{1}{c}{ Results } \\
\hline ISA & Fan Speed \# 1 & USA & Success \\
ISA & Fan Speed \# 1 & ISSA & Fail \\
ISA & Fan Speed \# 1 & USA & Fail \\
ISA & Fan Speed \# 1 & ISA & Success \\
ISA & Fan Speed \# 1 & ISA & Success \\
ISA & Fan Speed \# 1 & ISA & Success \\
ISA & Fan Speed \# 1 & USA & Fail \\
ISA & Fan Speed \# 1 & USA & Fail \\
ISA & Fan Speed \# 1 & ASAP & Fail \\
ISA & Fan Speed \# 1 & ISA & Success \\
\hline Mean Average & & & $50 \%$ \\
\hline \hline
\end{tabular}

Table 2: Fan Speed No.2 Testing Results

\begin{tabular}{cccc}
\hline \hline Voice Input & Expected Output & Actual Output & Results \\
\hline IKALAWA & Fan Speed \#2 & IKALAWA & Success \\
IKALAWA & Fan Speed \#2 & IKALAWA & Success \\
IKALAWA & Fan Speed \#2 & IKALAWA & Success \\
IKALAWA & Fan Speed \#2 & IKALAWA & Success \\
IKALAWA & Fan Speed \#2 & IKALAWA & Success \\
IKALAWA & Fan Speed \#2 & IKALAWA & Success \\
IKALAWA & Fan Speed \#2 & IKALAWA & Success \\
IKALAWA & Fan Speed \#2 & IKALAWA & Success \\
IKALAWA & Fan Speed \#2 & IKALAWA & Success \\
IKALAWA & Fan Speed \#2 & IKALAWA & Success \\
\hline Mean Average & & & $100 \%$ \\
\hline \hline
\end{tabular}

Table 3: Fan Speed No.3 Testing Results

\begin{tabular}{rrrr}
\hline \hline \multicolumn{1}{c}{ Voice Input } & Expected Output & Actual Output & Results \\
\hline IKATLO & Fan Speed \#3 & IKATLO & Success \\
IKATLO & Fan Speed \# 3 & IKATLO & Success \\
IKATLO & Fan Speed \#3 & IKATLO & Success \\
IKATLO & Fan Speed \#3 & IKATLO & Success \\
IKATLO & Fan Speed \#3 & IKATLO & Success \\
IKATLO & Fan Speed \#3 & IKATLO & Success \\
IKATLO & Fan Speed \#3 & IKATLO & Success \\
IKATLO & Fan Speed\#3 & IKATLO & Success \\
IKATLO & Fan Speed \#3 & IKATLO & Success \\
IKATLO & Fan Speed \#3 & IKATLO & Success \\
\hline Mean Avcrage & & & $100 \%$ \\
\hline \hline
\end{tabular}

Table 4: Fan Speed No.4 Testing Results

\begin{tabular}{rrrr}
\hline \hline Voice Input & Expected Output & \multicolumn{1}{c}{ Actual Output } & \multicolumn{1}{c}{ Results } \\
\hline PATAYIN & Fan OFF & PATATIM & Fail \\
PATAYIN & Fan OFF & PATAYIN & Success \\
PATAYIN & Fan OFF & PATAYAN & Fail \\
PATAYIN & Fan OFF & PATAYIN & Success \\
PATAYIN & Fan OFF & PATAYIN & Success \\
PATAYIN & Fan OFF & MADALIN & Fail \\
PATAYIN & Fan OFF & PATAYIN & Success \\
PATAYIN & Fan OFF & PATATIM & Fail \\
PATAYIN & Fan OFF & PATAYIN & Success \\
PATAYIN & Fan OFF & PATAYIN & Success \\
\hline Mean Average & & & $60 \%$ \\
\hline \hline
\end{tabular}

Table 1-4 shows the results of the testing conducted to evaluate the accuracy of the voice recognition in giving commands such as turning-on and turning-off the electric fan and changing the speed of the electric fan from speed 1 to speed no. 4 controlled by voice recognition using Filipino language like ISA for speed no.1, IKALAWA for speed no.2, IKATLO is speed no. 3 and PATAYIN for Speed no. 4 .

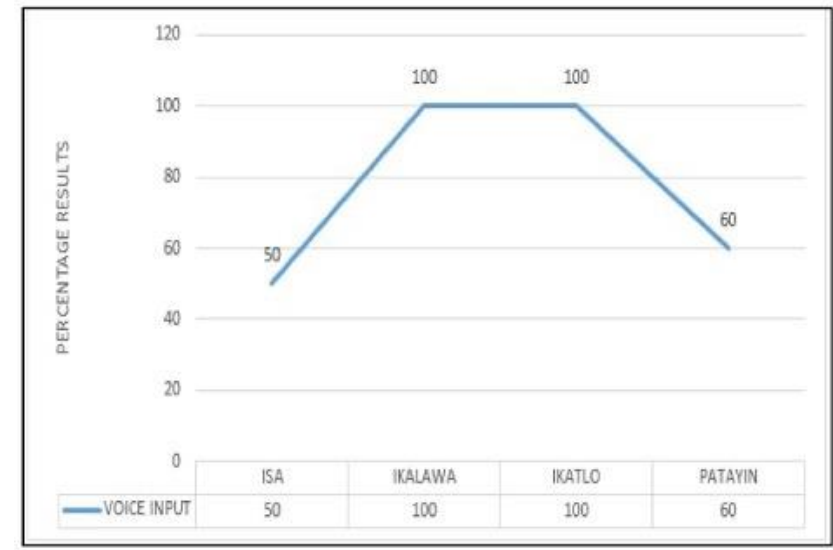

Figure 7: Fan-speed Voice Recognition Control System

The graph presented beforehand is computed based on the equation: [(True Value - Actual Value) / True Value] x 100. Through this, the success rate can be acquired which are shown in Tables 1, 2, 3, and 4.

Based on the results, the Filipino voice commands, "IKALAWA" and "IKATLO" show the highest percentage of accuracy with a $100 \%$ success rate. However, the command, "ISA" yields 50\% and "PATAYIN" has 60\%. These experiments are conducted in a quiet environment.

\section{CONCLUSION}

Voice can be captured faster than writing or typing, therefore, voice recognition is much more efficient to use. The data will be gathered easier if the voice is used since verbal input is much better rather than using your body movement. In terms of speed, the system could capture the user's speech at a faster rate rather than moving towards the electric fan alone. It is very helpful to make notations direct and simple.

The accuracy rates are exceeded by speech recognition technologies. This benefit reduces the need for several phases which includes individuals that allow jobs for everybody else automatically.

This tool will be very suitable for people with a disability but could talk. It is very difficult for people with quadriplegia or similar disabilities to move. It could minimize and eliminate constraints to handicap accessibility, and provide a safe environment for the users and nonusers. Since the language is in Tagalog, Filipinos would not have to be bothered by not knowing the universal language. 


\section{ACKNOWLEDGEMENT}

The proponent would like to thank the Isabela State University-Echague campus for all the financial assistance and computing facilities to make this paper possible to be published.

\section{REFERENCES}

1. J. Sedivy and J. Chromy, Research of Communication Activities Using Electronic Devices in Education, Procedia - Social and Behavioral Sciences, vol. 191, pp. 1983-1990, 2015. doi: 10.1016/j.sbspro.2015.04.266

2. X. Hua, Research on Remote Control Technology, Advanced Materials Research, vol. 722, pp. 369-373, 2013. doi: 10.4028/www.scientific.net/amr.722.369

3. M. Grossman, D. Zak and E. Zelinski, Mobile Apps for Caregivers of Older Adults: Quantitative Content Analysis, JMIR mHealth and uHealth, vol. 6, no. 7, p. e162, 2018. doi: 10.2196/mhealth.9345

4. J. van Erp, L. Kroon, T. Mioch and K. Paul, Obstacle Detection Display for Visually Impaired: Coding of Direction, Distance, and Height on a Vibrotactile Waist Band, Frontiers in ICT, vol. 4, 2017. doi: 10.3389/fict.2017.00023

5. H. Singh, S. Verma, S. Pal and K. Pandey, A step towards Home Automation using IOT, 2019 Twelfth International Conference on Contemporary Computing (IC3), 2019. doi: 10.1109/ic3.2019.8844945

6. S. Uma, R. Eswari, R. Bhuvanya and G. Kumar, IoT based Voice/Text Controlled Home Appliances, Procedia Computer Science, vol. 165, pp. 232-238, 2019. doi: 10.1016/j.procs.2020.01.085

7. C. Yue and S. Ping, Voice activated smart home design and implementation, 2017 2nd International Conference on Frontiers of Sensors Technologies (ICFST), 2017. doi: 10.1109/icfst.2017.8210563

8. A. Chern, Y. Lai, Y. Chang, Y. Tsao, R. Chang and H. Chang, A Smartphone-Based Multi-Functional Hearing Assistive System to Facilitate Speech Recognition in the Classroom, IEEE Access, vol. 5, pp. 10339-10351, 2017. doi: 10.1109/access.2017.2711489

9. K. Mandula, R. Parupalli, C. Murty, E. Magesh and R. Lunagariya, Mobile based home automation using Internet of Things(IoT), 2015 International Conference on Control, Instrumentation, Communication and Computational Technologies (ICCICCT), 2015. doi: 10.1109/iccicct.2015.7475301

10. W. Hartman, A. Hansen, E. Vasquez, S. El-Tawab and K. Altaii, Energy monitoring and control using Internet of Things (IoT) system, 2018 Systems and Information Engineering Design Symposium (SIEDS), 2018. doi: 10.1109/sieds.2018.8374723

11. C. Cheng and D. Lee, Enabling Smart Air Conditioning by Sensor Development: A Review, Sensors, vol. 16, no. 12, p. 2028, 2016. doi: $10.3390 / \mathrm{s} 16122028$
12. M. Afify, A. Abuabed and N. Alsbou, Smart engine speed control system with ECU system interface, 2018 IEEE International Instrumentation and Measurement Technology Conference (I2MTC), 2018. doi: 10.1109/i2mtc.2018.8409871

13. C. Baby, N. Munshi, A. Malik, K. Dogra and R. Rajesh, Home automation using web application and speech recognition, 2017 International conference on Microelectronic Devices, Circuits and Systems (ICMDCS), 2017. doi: 10.1109/icmdcs.2017.8211543

14. K. Joshi, R. Ranjan, E. Sravya and M. Baig, Design of Voice-Controlled Smart Wheelchair for Physically Challenged Persons, Advances in Intelligent Systems and Computing, pp. 79-91, 2018. doi: 10.1007/978-981-13-1501-5_7

15. A. Nassif, I. Shahin, I. Attili, M. Azzeh and K. Shaalan, Speech Recognition Using Deep Neural Networks: A Systematic Review, IEEE Access, vol. 7, pp. 19143-19165, 2019. doi: 10.1109/access.2019.2896880

16. D. Prabakaran and R. Shyamala, A Review On Performance Of Voice Feature Extraction Techniques, $20193 \mathrm{rd}$ International Conference on Computing and Communications Technologies (ICCCT), 2019. doi: $10.1109 /$ iccet2.2019.8824988

17. K. R., N. K., P. S. and S. T., Voice and speech recognition in Tamil language, 2017 2nd International Conference on Computing and Communications Technologies (ICCCT), 2017. Available: 10.1109/iccet2.2017.7972293

18. H. Miyoshi, Y. Saito, S. Takamichi and H. Saruwatari, Voice Conversion Using Sequence-to-Sequence Learning of Context Posterior Probabilities, Interspeech 2017, 2017. doi: 10.21437/interspeech.2017-247

19. A. Alon and J. Susa, Wireless Hand Gesture Recognition for an Automatic Fan Speed Control System: Rule-Based Approach, 2020 16th IEEE International Colloquium on Signal Processing \& Its Applications (CSPA), $2020 . \quad$ doi: 10.1109/cspa48992.2020.9068687

20. C. Casuat, Biofuz: A Takagi Sugeno Fuzzy Expert-Based Rice Straw Enhanced Decomposition System, International Journal of Advanced Trends in Computer Science and Engineering, vol. 9, no. 2, pp. 2168-2172, 2020. doi: 10.30534/ijatcse/2020/192922020

21. A. Alon, SmaCk: Smart Knock Security Drawer Based on Knock-Pattern using Piezo-electric Effect, International Journal of Emerging Trends in Engineering Research, vol. 8, no. 2, pp. 339-343, 2020. doi: $10.30534 /$ ijeter/2020/16822020

22. M. F. Malbog, A Fuzzy Rule-Based Approach for Automatic Irrigation System through Controlled Soil Moisture Measurement, International Journal of Advanced Trends in Computer Science and Engineering, vol. 9, no. 2, pp. 2332-2337, 2020. doi: 10.30534/ijatcse/2020/216922020

23. J. B. Susa, Automatic Room Humidifier and Dehumidifier Controller using Arduino Uno, International Journal of Advanced Trends in 
Computer Science and Engineering, vol. 9, no. 2, pp. 2208-2212, 2020. doi: 10.30534/ijatcse/2020/198922020

24. J. Mindoro, Drowsy or Not?Early Drowsiness Detection utilizing Arduino Based on Electroencephalogram (EEG) Neuro-Signal, International Journal of Advanced Trends in Computer Science and Engineering, vol. 9, no. 2, pp. 2221-2226, 2020. doi: 10.30534/ijatcse/2020/200922020

25. J. So Gulmatico, Tracking Utilizing Accelerometer and Piezoelectric Sensor, International Journal of Emerging Trends in Engineering Research, vol. 8, no. 2, pp. 515-519, 2020. doi: 10.30534/ijeter/2020/39822020 